\title{
The fantasy of the natural/cultural elements as symbolic tourist attractions through senses and technology
}

\author{
Ana PEREIRA NETO \\ CHAM, FCSH, Universidade NOVA de Lisboa, and ISEC Lisboa \\ Email: ananeto@fcsh.unl.pt; ana.pereiraneto@iseclisboa.pt \\ ORCID: 0000-0002-0954-1220
}

\begin{abstract}
The purpose of this paper is to understand the importance of the traditional knowledge on the use of space and events organisation, in the hedonistic practices associated with leisure and creative processes in tourism innovation, throughout new forms of intelligence, such as the artificial one, better known as A.I. We cannot dissociate this kind of so-called intelligence from the authenticity of the memories that are still remembered by the real agents of culture- the people who live in the places that are visited by tourists. And these are the ones who can capture the interest of these visitors, arousing it with the explanations of their sensorial stimulation; this is already possible for a better comprehension of the usage of culture in visited places. It is on the excellent use of communication, by its awareness, that we can get better learning for the heritage safeguarding.

By our knowledge based on long-term ethnographic immersion on the Portuguese rurality, and in the bibliographic review, we propose the usage of the communication based on the traditional wisdom that can be taught by the locals, in tourism sites, and on media applications. The creation of attractions in tourism must be equational to the primacy of ethical principles with culture and technology.
\end{abstract}

Keywords: tourism, heritage, senses, creativity, technology

\section{Introduction}

There is an increasing interest in demand on reality and identity, but the individualism concerning preferences causes problems of adaptation to supply tourism services. The latter tends to take more time to adjust strategically to the new realities and sometimes with a significant loss in the thread of identities. It is essential to understand the criteria that reveal representations, cultural models and environments to comprehend the creative process of these identities. Knowing that there are no fixed descriptions, the requirements can change, and the notion of demand can be constructed in different ways, from different premises, which does not invalidate the need to preserve identity-based on the heritage legacy, constituted as implicit or explicit memory.

With the plurality of information available, one tends to use that which was already known and used for the same purpose. There is a certain laxity in the face of the accurate representation of reality. The actual experiences in the visited places are, when authentic, a multiplier effect in the returning visitors and first time ones.

More than the real image, it is the experience that sets the right information. Hence, we consider the importance of the ethical awareness of the authenticity of who is involved in the whole supplying service.

Culture, like tourism, involves issues of exchange and the relationship between what is given and received, between creation and contemplation, and these relationships depend on the crossing of two axes: the guest/host population and the heritage. It is in this dynamics that the communicational process can produce an attractional factor to tourism sites.

Without knowledge, there can be no noteworthy reading on the heritage, including the natural one, and therefore there can be no quality in hosting integration, based on authenticity and genuineness.

It is in this sense that we propose the valuation of information about heritage through the sensory impressions that can be taught by communication technologies, using the local cultural codes of interpretation, using the memories of the locals that still remember.

We make a brief presentation of the vantages and disadvantages of the use of technologies, in touristic frequency, concerning with the audio, visual, odour and tact, in the communication between the user guest and the localhost.

\section{Authenticity through the interpretation of natural and cultural systems}

For the maintenance of natural and cultural heritage, there must be a correct understanding of its meaning as well as its intrinsic significance.

Dynamics of identity maintenance and projection are necessary, based on the history of space, where the traits and elements that characterise cultural originality reside, still recognised by the inhabitants of most of the places we seek to know as tourists. 
These traits can be rapidly perceived by individual research in media platforms or the visited places. However, there can be several misunderstandings of the real site itself.

When someone describes the sites makes it with one's perception and codes of interpretation. Smart Tourism instead of being a significant data information facilitator to stakeholders (Buhalis,D.\& Amaranggana, A. 2013) has to become more communicative. Sometimes the wrong information is passed by its producers on the tourism sites, inferred by economic interests, most of the time. (Soukhathammavong, B., \& Park, E., 2019).

Landscape and urban places have their own stories to tell, and these must be integrated into a learning process based on an intelligible communicational process.

Beacons as a form of technology that can provide information in consumerism places, like shopping malls, or in nature itself, are used as a provider of information of data sites. However, a significant part of that information is just a part of the stories that can be told. (Neto, Ana Pereira and Mateus, 2017).

These technological devices are very interesting, concerning the attribution of economic value to local spaces and products; but the information they convey lacks the interpretative value of who is heir to the tradition - the local population - who is the interpretive facilitator par excellence, of the contents of the domestic spaces inserted in the regional context.

The customer using this technology can interact with the application and then the places where it consumes; this ensures the individualisation of choice and informational feedback but does not guarantee the quality of the information, which should operate in a broader context.

Direct communication can bring magic to the visited places and stimulates fantasy to the ones who attend them, and thus can bring more attractional factors to sites. Real identification must be taught; otherwise, the interpretative discourse could be distorted, and fantastic stories can pass to newcomers without pedagogical significance.

\section{Visual and odour senses}

These senses are implicitly joined in most of the touristic experiences. Some products like the ones related to food and beverage are integrated into marketing communication to promote destinations.

Food and culinary techniques relate to the regional marketing in which they constitute just a part of the metaphorical information (Berg, P. O., \& Sevón, G. 2014).

This information requires qualification throughout the certification of traditional products, as an institutional procedure. However, this does not contemplate the information that comes from previous ethnographic and ethnological studies. This fact and the disregard for the knowledge of the local producers, which remains a secret to the public domain, can bring some annoyance to the few ones that still remember the right procedures in the creation of the real local flavour.

The formal aspect of Portuguese ceremonial pastry can be appreciated if its ethnological information is passed to consumers; that is the case of folares, sonhos, espécies, amongst many others. Their shapes can tell many interesting stories that can be related to many others that are local identifiers of ethnic identity.

Tradition consumerism of these kind of commodities is embedded of profane symbolism, part of the intangible heritage that does not come to the public, namely the possible visitors. That happens with the use of olive oil or pork fat which has a visual effect that is unperceived without the explanation of the symbolic meaning of its use within the traditional calendar.

The odour of fried olive oil or pork oil can tell much of the importance of its use, for sacred/profane means. Its consumption can validate the quality of the experience, in the oeno/gastronomic context. Some natural ingredients used in some occasions can be trusted as fixers of traditional knowledge, and essential health keepers and, as well, attraction identifiers (Neto, Ana Pereira, 2015).The culinary techniques and traditional receipts that are enhancers of local identity can be safeguarded by technology.

The moderate doses of traditional natural ingredients in culinary techniques is nowadays one of our research issues. That is something that the visual presentation cannot identify. And, what about the odour?

The pastel de nata, one of the world's best-known Portuguese pastry elements is representative of the urban culture and is empty of traditional meaning. Its configuration, however, can have a wide range of odour interpretation than if it is shown only in pictures.

Odour wheels, nowadays used in city branding or specific places or cases, like archival paper (Bembibre, C., \& Strlič, M. 2017) can also be used in instructive ways, in mobile apps, as facilitators of daily interpretation for personal users.

The traditional codfish with garlic cannot taste Portuguese tradition if it is not made with raw fresh garlic. It is already possible to associate odour to mobile phone apps, this technology is known for some years (Ranasinghe, Nimesha, et al. 2011) and can be perfected in associating images to "tastes". The explanation of the smelly tradition can be made with personal hosts avatars, like those created by ObEN, Artificial Intelligence Inc., on the Project Personal Artificial Intelligence -PAI. (Du, J., Fang, D., 
\& Harvilla, M. 2019).

Through A.I. applications on mobile phones, these avatars can interact with the user and speak several languages, although they can only transmit information for what they are programmed for (Wagner, 2018).

The identification of ingredients, using the knowledge and its appliance in a local touristic promotional site, seems to us of interest, especially if this can be done using A.I. storytelling, with the advantage of multilingual speech use.

\section{Sonic Sense}

Symbolic perception of sonic experiences and its interpretation in tourism promotion require our attention, namely in everything that concerns the authenticity and its certification.

The data concerning information on sonic heritage is, like other information for tourists, well-kept and used in several ways, although dispersed in the available interpretation to users.

Sound can help fixing memories, and the sonic experiences can bring awareness of olfactory and visual issues on the visited places. The use of sound traces to explain cultural elements, by A.I technology, seems to us a perfect way to facilitate the holistic sensuous perception of local culture to tourists. However, the local codes of interpretation have to be given in an intelligible form.

Cante, as UNESCO intangible heritage (Raposo, Eduardo M. and Neto, Ana Pereira, forthcoming) is an example of the importance of the cultural, spatial context for authentic performance. However, how can this be explained to someone that does not relate the several meanings of that context?

The sonic effect that the singers can produce in a tavern or an open space has its particularities; these are identifiers of behavioural performing actions. The listener is aware of the difference, but cannot perceive the whole message that comes from the group.

Personal hosts are excellent interpreters; however, they are often used for groups of tourists that come to spaces in a disturbing way, as spectators.

Reduction of the impact that the number of incomers can produce in a space where this chant tradition emerge can also be one of the advantages of the use of the referenced technology.

Sound as an interpretative way of places, has often been used in its branding, especially in urban areas related to the musical genre that configures some of the typicity of the sites. This use is done mostly for marketing purposes of the stakeholders involved in tourism. Thus, the attraction factor is, someway, manipulated, and voids its symbolism. In itineraries, sonic experiences can be enlarged in its range, covering the territory focusing attention to several components of the environment such as the cultural and the natural ones. These can be separated for a better perception of different times in the past. The awareness of aroused memories from the past and its projection for a new future should be useful as a recreational fantasia, based upon real data collection.

Times of remembrance of the sounds produced by men, domestic animals, individual calls made by people in certain hours of the day can imprint their mark for a better perception of local identity.

Places of the southern coastal line of Portugal are being lived and sold as part of the marketing clichés, proposed by stakeholders. Everything seems similar to other contexts, and even the new generations of locals do not recognise in nature the stories and legends of their ancestors

It is with certain anguish that we do not see any more tourists who come exclusively to feel the experience of hearing the sonic purity of the wave spraying, or the donkeys braying when the evening is coming. However, it is possible to do experience phantasy with the right mobile application, without crowd disturbance.

\section{Touch Sense}

And what about touch? How can it be interpreted? Spoken and written word use can be a useful tool, conjoined with the others that we referred to previously.

The importance of traditional materials used in the primary production technologies in gastronomy, in weaving, ceramics and shelter/habitation, are fundamental for a better comprehension of the visited whole. Its explanation, focusing the arousal of this sense, is not commonly used for individual tourists.

Museums are the privileged places for this kind of cultural appreciation; however, the readings that users have from the exhibits are only a partial component, subdued to thematic schemes, of the possible interpretations that new technologies can bring.

The exhibition time can be permanent or temporary, and the possibilities of crossed information and its interpretation fix in closed spaces, reducing touching experiences, which are, most of the times, forbidden.

The use of samples, for touch purpose, from original materials is reductive for observation and integration in the communicative process of knowledge transmission. Texture, for example, must be explained in its entire context, not disregarding all the procedures of its elaboration.

Here, once more, the representation odour wheels can be associated with odour applications transmitters. It is also possible, nowadays by the use of augmented virtual reality, known as A.R., to provide touch experiences in diverse portable ways, like prints (Olalde, Karle. Guesalaga, Imanol 
2013).

\section{Final notes}

Portability and individual use of knowledge provided by technology can be facilitators of heritage safeguarding, in a self-educational way. The portable applications can be used freely, without the preoccupation of limitations based on time and spatial distance. Thus, the constraints of time schedules of overture and closure of nature/cultural interpretation centres are postponed.

We cannot ignore the possibilities that A.I. technology has in its communicational range. However, the knowledge that resides out of the big data servers, and its importance like all the work done by researchers in several areas of science, namely in the almost forgotten Anthropology, must gain its role to its enrichment.

A.l. technology has several advantages in transferring knowledge, throughout chatterbots and avatars; however, there is a long way to go to explain symbolic thought, which is fundamental to comprehend the culture in all its ranges.

Sensuous explanations seem of an exciting area to exploit, nowadays and soon, where nature and memories appear to be things that must come out to the light of comprehension, to the ones that live in times where the past only comes out when is called. However, it may never come if no one is aware of its existence

Memory data must include in a dynamic communicational process, as interest enhancers, through its usage, by everyone.

Quality of the information vehiculated by these kinds of technologies must rely on as a trustful mean of ethical principles, which cannot subdue to economic based interests.

Thus it can safeguard the heritage specificities of each bio-socio-cultural system; the attraction factor for the demand of diversity can be used as an element of qualification to those systems.

Acknowledgement:

This chapter had the support of CHAM (NOVA FCSH/UAC), through the strategic project sponsored by FCT (UID/HIS/04666/2019)

\section{Bibliographical References}

Bembibre, C., \& Strlič, M. (2017). Smell of heritage: A framework for the identification, analysis and archival of historic odours. Heritage Science, 5(1). https://doi.org/10.1186/s40494-016-0114-1

Berg, P. O., \& Sevón, G. (2014). Food-branding places - A sensory perspective. Place Branding and Public Diplomacy, $\quad 10 \quad$ (4), $\quad$ pp.289-304. https://doi.org/10.1057/pb.2014.29

Buhalis, D., \& Amaranggana, A. (2013). Information and
Communication Technologies in Tourism 2014. EProceedings of the ENTER 2014 PhD Workshop, 1146. https://doi.org/10.1007/978-3-319-03973-2

Du, J., Fang, D., \& Harvilla, M. (2019). PAI Data, Summary of the Project PAI Data Protocol.

Neto, Ana Pereira, and Mateus, Anabela Félix. (2017). Turismo de Saúde e Bem-Estar. A informação Comunicação como atractivos termais. Um caso: As Caldas da Rainha. In Perfiles actuales en la información y lo informadores. Ediciones Universitarias. pp. 365-377. Editorial TECNOS (Grupo Anaya). ISBN 978-84-309-7378-1.

Neto, Ana Pereira. (2015). Termalismo- As lógicas do consumo na entropia da ordem cultural, o exemplo das Caldas da Rainha. (PhD). Universidade Nova de Lisboa. http://hdl.handle.net/10362/14498

Olalde, Karle, Guesalaga, Imanol. (2013). The New Dimension in a Calendar: The Use of Different Senses and Augmented Reality Apps. Procedia Computer Science, ISSN: 1877-0509, Vol: 25, pp: 322-329.

https://doi.org/10.1016/j.procs.2013.11.038

Ranasinghe, Nimesha, et al. (2011). Digital taste and smell communication. In Proceedings of the 6th International Conference on Body Area Networks., (78-84).Brussels: ICST (Institute for Computer Sciences, Social-Informatics and Telecommunications Engineering.

Raposo, Eduardo M. and Neto, Ana Pereira. (forthcoming). Cante Intangible Cultural Heritage of Humanity: representation of a traditional art in the city of Almada In AMPS Proceedings Series Tangible Intangible Heritage(s)Design, Social and Cultural Critiques on the Past, Present and the Future. London: the University of West of London.

Soukhathammavong, B., \& Park, E. (2019). The authentic souvenir: What does it mean to souvenir suppliers in the heritage destination? Tourism Management, 72,105-116

https://doi.org/10.1016/j.tourman.2018.11.015

Wagner, Kurt (2018). I talked to Google's Duplex voice assistant. It felt like the beginning of something big. But it's not even close to ready for everyday use. https://www.recode.net/2018/6/27/17508166/go ogle-duplex-assistant-demo-voice-calling-ai. 